\title{
In vitro infection of Madin-Darby bovine kidney (MDBK) cells with Eimeria acervulina sporozoites: quantitative analysis of parasite cellular invasion and replication using real-time polymerase chain reaction $(P C R)$
}

\author{
Shahinaz Taha ${ }^{1,2}$ (Tran Nguyen-Ho-Bao ${ }^{1,3} \cdot$ Arwid Daugschies $^{1,4} \cdot$ Zaida Rentería-Solís $^{1,4}$
}

Received: 8 February 2021 / Accepted: 7 June 2021 / Published online: 19 June 2021

(c) The Author(s) 2021

\begin{abstract}
Poultry coccidiosis causes considerable economical losses to the livestock industry. Eimeria parasites are responsible for this disease. On a global scale, E. acervulina and E. tenella are amongst the most common Eimeria spp. infecting broilers. E. tenella is commonly used as infection model in in vivo and in vitro studies. On the other hand, E. acervulina has barely been studied under in vitro conditions. A well established and widely used in vitro model for $E$. tenella infection is the MadinDarby bovine kidney cell line (MDBK); however, little is known regarding suitability of MDBK cells as host cells for $E$. acervulina. We infected MDBK monolayers with two different doses, $5 \times 10^{4}$ and $2 \times 10^{5}$, of E. acervulina sporozoites and evaluated cultures at 24 and $96 \mathrm{~h}$ post infection (hpi). For comparison, we ran an identical infection assay using E. tenella sporozoites. To assess parasite reproduction, the number of DNA copies of E. acervulina SCAR marker and $E$. tenella ITS-1 gene was quantified using real-time quantitative PCR. We found that the number of E. acervulina copies increased significantly at $24 \mathrm{hpi}$ in comparison to E. tenella $(p<0.05)$. After $96 \mathrm{hpi}, E$. acervulina gene copies were considerably reduced while E. tenella continued to multiply $(p<0.05)$. Our results show that MDBK monolayers could be used for in vitro research aimed to study E. acervulina sporozoite cell invasion. Nevertheless, modifications of in vitro cultivation appear necessary to allow qualitative and quantitative studies over longer periods of parasite reproduction.
\end{abstract}

Keywords Coccidiosis $\cdot$ Eimeria acervulina $\cdot$ Eimeria tenella $\cdot$ Poultry $\cdot$ MDBK cells

\section{Introduction}

Section Editor: Daniel K Howe

Shahinaz Taha

shahinazvet2011@hotmail.com

1 Institute for Parasitology, Centre for Infectious Diseases, Faculty of Veterinary Medicine, University of Leipzig, An den Tierkliniken 35, 04103 Leipzig, Germany

2 Department of Preventive Medicine and Veterinary Public Health, Faculty of Veterinary Medicine, University of Khartoum, Shambat, PO Box 32, 13314 Khartoum North, Sudan

3 Department of Veterinary Medicine, College of Agriculture, Can Tho University, 900000 Can Tho, Vietnam

4 Albrecht-Daniel-Thaer Institute, An den Tierkliniken 29, 04103 Leipzig, Germany
Coccidiosis is an economically important malady in the poultry industry (Blake et al. 2020). The disease is caused by apicomplexan parasites of the Eimeria genus. Infection occurs via oral ingestion of sporulated oocysts. Once in the host, the oocysts release sporozoites which invade the intestinal epithelial cells. Inside the host cells, sporozoites undergo asexual and sexual multiplication cycles. Oocysts are thereby produced and consequently shed in the feces. Infected animals can present weight loss, diarrhea, low egg production, and the disease can be fatal in some cases (López-Osorio et al 2020).

Seven species of Eimeria (E. acervulina, E. brunetti, E. maxima, E. mitis, E. necatrix, E. praecox, and E. tenella) are responsible for avian coccidiosis globally. Oocysts morphology, pathology, and severity of the disease are common differentiating factors amongst these species. From all seven 
Eimeria, E. acervulina, E. tenella, and E. maxima are the most prevalent in broiler farms (Jordan et al 2018; Moraes et al 2015; Györke et al 2013). Out of these 3 species, $E$. tenella is considered highly pathogenic while E. acervulina and E. maxima show moderate pathogenicity (López-Osorio et al. 2020). Notwithstanding variations in pathogenicity, moderate pathogenic Eimeria spp. such as E. acervulina could increase the severity of the disease during co-infection (Hiob et al. 2017).

Animal models are a valuable element in infection research. However, in vitro studies of coccidian parasites can contribute to the baseline understanding of the disease on a cellular level (Marugán-Hernández et al. 2020, Bussiere et al. 2018, Thabet et al. 2017). Moreover, they can be a useful tool providing baseline data for future therapies (Thabet et al. 2017; Khalafalla et al. 2011). Due to its ability to grow in non-avian cell lines (Marugán-Hernández et al. 2020; Thabet et al. 2017), E. tenella has been widely used as model organism in in vitro research (Marugán-Hernández et al. 2020; Thabet et al. 2019, 2017; Khalafalla et al. 2011) and considerable efforts have been directed to E. tenella in vitro and in vivo research, including the use of molecular approaches such as real-time quantitative PCR (RT-qPCR) (Marugán-Hernández et al. 2020; Thabet et al. 2019, 2017; Hiob et al. 2017; Raj et al. 2013). Less efforts have been reported for other Eimeria species, including E. acervulina (Naciri-Bontemps 1976; Itagaki et al. 1974; Strout et al. 1965; Hiob et al 2017). The aim of this study was to evaluate in vitro invasion and replication of E. acervulina sporozoites in MDBK cell monolayers using real-time quantitative PCR.

\section{Materials and methods}

\section{Passage of E. acervulina and E. tenella oocysts}

Oocysts of E. acervulina and E. tenella were separately passaged in healthy 11-day-old chicks according to a modified method from Eckert et al. (1995). Sporulated oocysts were collected and stored in $4 \%$ potassium dichromate solution at $4{ }^{\circ} \mathrm{C}$ until further use.

\section{Purification and excystation of oocysts}

Oocysts of both Eimeria species were cleaned from the $4 \%$ potassium dichromate solution. Thereafter, sporozoites were excysted and purified according to the modified method described by Rentería-Solís et al. (2020).

\section{Cell culture}

Madin-Darby bovine kidney (MDBK) monolayers (DSMZ, Braunschweig, Germany) were used as infection model.
MDBK cells were seeded $\left(2 \times 10^{5}\right.$ cells/well $)$ in 24-well plates with Dulbecco's Modified Eagle's Medium (DMEM) supplemented with $10 \%$ fetal bovine serum (FBS), $100 \mathrm{IU}$ penicillin, $100 \mu \mathrm{g} / \mathrm{mL}$ streptomycin, and $2.5 \mu \mathrm{g} / \mathrm{mL}$ amphotericin and incubated at $37^{\circ} \mathrm{C}$ in an atmosphere of $5 \% \mathrm{CO}_{2}$ in air until they reached $80 \%$ confluency.

\section{Infection of MDBK cells with Eimeria sporozoites}

Confluent MDBK monolayers were inoculated with E. acervulina sporozoites. Preliminary studies were performed in order to select an infection doses based on different multiplicity of infection (MOI) rates (parasite:cell): $0.25,0.5$, 1.0, 1.5, and 5.0 (Taha et al. unpublished data). Two separate doses were selected for infection: $5 \times 10^{4}$ (MOI: 0.25) or $2 \times 10^{5}$ sporozoites/well (MOI: 0.5 ). Cultures exposed to infection were then incubated at $41{ }^{\circ} \mathrm{C}$ in DMEM medium with $2 \%$ FBS, $100 \mathrm{IU}$ penicillin, $100 \mu \mathrm{g} / \mathrm{mL}$ streptomycin, and $2.5 \mu \mathrm{g} / \mathrm{mL}$ amphotericin. Two different incubation times were implemented: $24 \mathrm{~h}$ post infection (hpi) and 96 hpi. An identical set of infection doses and incubation times was conducted for E. tenella sporozoites. All experiments included one negative control consisting of uninfected MDBK monolayers (NC-uninfected cells). All assays were performed in triplicates. After $24 \mathrm{hpi}$, cells were washed three times with sterile PBS ( $\mathrm{pH} 7.2$ ) and new medium was added to the 96 hpi group whereas the 24 hpi cultures were terminated. Monolayers were trypsinized at the end of each incubation period ( $24 \mathrm{hpi}$ or $96 \mathrm{hpi}$, respectively).

\section{DNA extraction and real-time quantitative polymerase chain reaction (RT-qPCR)}

DNA was extracted from the trypsinized cells using the DNeasy Blood \& Tissue kit (Qiagen, Hilden, Germany) according to the manufacturer's protocol. RT-qPCR was performed to quantify copies of E. acervulina sequence characterized amplified region (SCAR) marker Ac-R01-1731 and for E. tenella internal transcribed spacer 1 of ribosomal DNA (ITS-1) gene as correlate of parasite replication. RT-qPCR assays were conducted according to the methods described by Blake et al. (2008) and Kawahara et al. (2008), respectively, with some modifications. Briefly, a $20 \mu \mathrm{l}$ volume reaction contained $10 \mu \mathrm{l}$ SYBR Green ${ }^{\circledR}$ master mix (Thermo Scientific, Dreieich, Germany), $500 \mathrm{nM}$ of forward and reverse primers (Table 1), $2 \mu \mathrm{l}$ of DNA template, and $7 \mu \mathrm{l}$ nuclease-free water. A non-template control (NTC) consisting of nuclease-free water was added to each assay. RTqPCR reactions were amplified in triplicates and conducted on a Bio-Rad CFX Connect Real-Time PCR Detection System (Bio-Rad, Feldkirchen, Germany). RT-qPCR conditions were $95^{\circ} \mathrm{C}$ for $5 \mathrm{~min}$ followed by 40 cycles of $95^{\circ} \mathrm{C}$ for $30 \mathrm{~s}$. Annealing was performed at $59.8^{\circ} \mathrm{C}$ and $58^{\circ} \mathrm{C}$ for $20 \mathrm{~s}$, for 
Table 1 Species-specific set of primers for real-time quantitative PCR

\begin{tabular}{lllc}
\hline Oligonucleotide identity & Primer sequences (5' to 3') & $\begin{array}{l}\text { Amplicon size (base } \\
\text { pairs) }\end{array}$ & References \\
\hline E. acervulina forward & Eac_qPCRf CTCGCGTGTCAGCACTACAT & 124 & Blake et al. (2008) \\
$\begin{array}{l}\text { E. } \text { acervulina } \text { reverse } \\
\text { E. } \text { tenella } \text { forward }\end{array}$ & Eac_qPCRr GATAGCGTGCTTTGCCTTTC & & Kawahara et al. (2008) \\
E. tenella reverse & Et_qPCRf TGGAGGGGATTATGAGAGGA & 147 & \\
\hline
\end{tabular}

E. acervulina and E. tenella, respectively, followed by one extension cycle of $20 \mathrm{~s}$ at $72{ }^{\circ} \mathrm{C}$. A melting curve program was applied involving a temperature range from 60 to $95{ }^{\circ} \mathrm{C}$ to create a dissociation curve. Finally, E. acervulina and $E$. tenella standard curves were generated by a serial dilution of genomic DNA and a serial dilution of cloned ITS-1 gene fragments (according to Thabet et al. 2015), respectively.

\section{Statistical analysis}

D'Agostino-Pearson and Shapiro-Wilk normality tests were used to determine normal distribution of data. A two-way ANOVA test was used for comparison of reproduction considering time points, infection doses, and Eimeria species. Differences were considered statistically significant when $p>0.05$. All statistical analysis were made in GraphPad prism 9 software (San Diego, CA, USA).

\section{Results and discussion}

Gene copies of $E$. acervulina SCAR marker and E. tenella ITS-1 gene were successfully amplified and detected through RT-qPCR in every reaction. After an incubation period of 24 hpi, the number of copies detected after application of a dose of $5 \times 10^{4}$ sporozoites was significantly higher $(p=0.0002)$

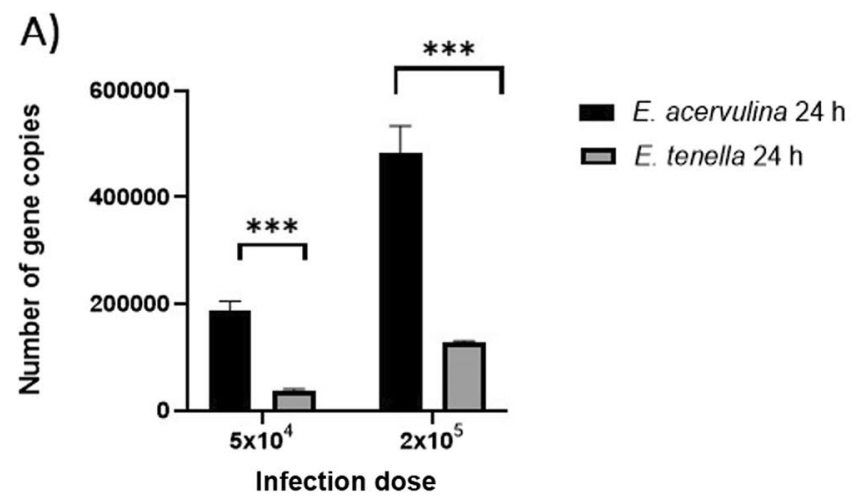

Fig. 1 E. acervulina and E. tenella parasite multiplication. A Comparison between $E$. acervulina and $E$. tenella number of copies detected 24 hpi. B Comparison between E. acervulina and E. tenella for $E$. acervulina $\left(1.88 \times 10^{5} \pm 5.56 \times 10^{4}\right)$ than for $E$. tenella $\left(3.60 \times 10^{4} \pm 5.37 \times 10^{3}\right)($ Fig. 1$)$. Similarly, a significantly higher $(p=0.0002)$ number of copies were obtained for E. acervulina $\left(4.82 \times 10^{5} \pm 8.50 \times 10^{4}\right)$ than for E. tenella $\left(1.27 \times 10^{5} \pm 9.32 \times 10^{3}\right) 24$ hpi after application of $2 \times 10^{5}$ sporozoites (Fig. 1).

In contrast, 96 hpi following infection with $5 \times 10^{4}$ sporozoites, the number of copies in the E. acervulina infected cultures was significantly $(p=0.0044)$ lower $\left(6.96 \times 10^{3} \pm 3.87 \times 10^{3}\right)$ as compared to E. tenella $\left(1.24 \times 10^{5} \pm 1.01 \times 10^{5}\right)$. Likewise, the higher dose of $2 \times 10^{5}$ sporozoites incubated with monolayers for the longer period of 96 hpi resulted in significantly $(p=0.0044)$ lower quantities of E. acervulina copies $\left(3.35 \times 10^{4} \pm 1.53 \times 10^{4}\right)$ in comparison with E. tenella $\left(4.98 \times 10^{5} \pm 1.28 \times 10^{5}\right)$ (Fig. 1).

We tested the ability of $E$. acervulina to invade MDBK monolayers and to subsequently multiply over 24 and $96 \mathrm{hpi}$. Earlier attempts to evaluate E. acervulina culture have been conducted with variable results. Strout et al. (1965) infected different primary (chicken embryo kidney and fibroblasts) and permanent cell lines (mouse fibroblasts, HeLa cells). Strout et al. (1965) reported recognizable cell infection at 24 hpi in all cell lines. Interestingly, they did not observe parasitic growth over periods of more than 24 hpi in any of the tested cell models (Strout et al. 1965) which is in accordance with our observations of decreasing numbers of gene

B)

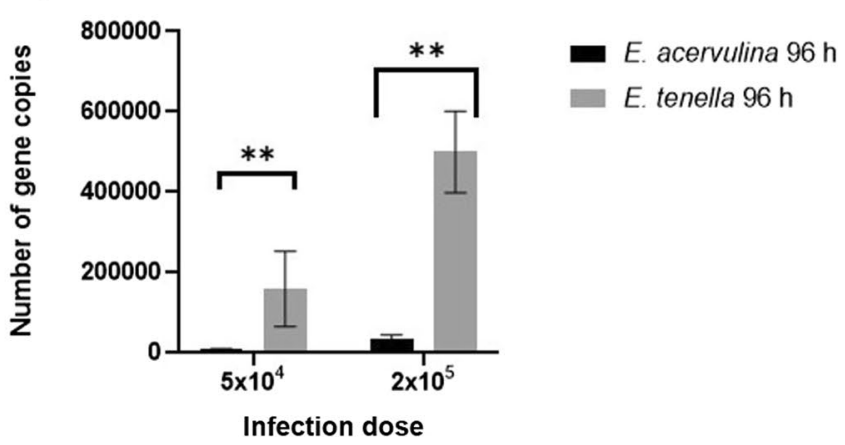

number of copies detected 96 hpi. $* * p<0.005, * * * p<0.0005$, infection doses: sporozoites/well 
copies 96 hpi. Naciri-Bontemps (1976) reported growth of $E$. acervulina in chicken kidney cells until $93 \mathrm{hpi}$ and observed oocyst formation after inoculation of merozoites. However, to the best of our knowledge, these findings were not confirmed by later publications.

Only one article has been published on MDBK monolayers infected with E. acervulina sporozoites (Talebi 2001). In short, the author exposed MDBK cells previously treated with hyperimmune chicken or rabbit antisera to E. acervulina sporozoites for $24 \mathrm{hpi}$. Cultures were stained and intracellular sporozoites were microscopically counted. Unfortunately, the study solely presents percentages of parasite inhibition by antiserum (Talebi 2001), and thus, conclusions on efficacy of infection in this model cannot be easily drawn. To our knowledge, no further attempts to use MDBK cells as infection model for E. acervulina have been reported.

In accordance to the findings of Strout et al. (1965), we observed peak parasite reproduction at $24 \mathrm{hpi}$ and a distinct decrease later represented by low copy numbers at $96 \mathrm{hpi}$. Strout et al. (1965) and Naciri-Bontemps (1976) reported qualitative data that originated from microscopy analysis only. However, RT-qPCR is a more accurate and sensitive means to assess parasite reproduction. In fact, RT-qPCR is nowadays commonly used for quantitative evaluation and has been established successfully to assess reproduction of coccidia (e.g., Marugán-Hernández et al. 2020, RenteríaSolís et al. 2020, Thabet et al. 2019, Bussiere et al. 2018, Hiob et al. 2017, Thabet et al. 2017, Raj et al. 2013, Khalafalla et al. 2011).

However, electron microscopy could provide valuable data for analysis of intracellular development of E. acervulina in MDBK cells. Therefore, it should be considered for further in vitro investigations of E. acervulina.

Theoretically, avian cell lines would be preferable as in vitro infection model for chicken Eimeria as they originate from the natural host and might allow more representative insight into interactions between parasite and host than mammal-derived cell cultures. However, most of the chicken cell cultures suitable for poultry coccidiosis research are primary lines (Bussiere et al. 2018, Strout et al. 1965; Naciri-Bontemps 1976). Primary cells have several limitations compared to permanent cultures. One is the general need for fresh animal tissue to start laboratory experiments, which may be related to a risk of contamination (Verma et al. 2020). Moreover, to obtain primary cells, animals have to be sacrificed which is in conflict with ethical considerations. Finally, standardization of primary cell lines may be related to difficulties.

Therefore, the use of immortalized cell lines is general practice in most research groups working on in vitro culture of avian coccidia. In general, mammal-derived permanent cultures are chosen, since they are easily available from commercial sources and tools like antibodies, markers, published protocols, genomic sequences, etc. are established, while this is not always the case for less commonly used chicken cell lines.

MDBK cells are a bovine-derived permanent line used as in vitro model for a broad variety of applications. MDBK cells are well established for in vitro studies on E. tenella (Marugán-Hernández et al. 2020, Rentería-Solís et al. 2020, Thabet et al. 2019, Bussiere et al. 2018, Thabet et al. 2017, Khalafalla et al. 2011). Marugán-Hernández et al. (2020), for example, conducted a comprehensive description of intracellular development of E. tenella in MDBK cells. In this study, the authors tracked via RT-qPCR and reverse-transcriptase real-time PCR cellular division and stage development of transgenic strains of $E$. tenella.

Our goal was to quantify E. acervulina multiplication in MDBK cells by PCR technology. To the best of our current knowledge, such data has not been published before. Morphological analysis was not considered in our experiment. However, it has been repeatedly (Marugán-Hernández et al. 2020, Thabet et al. 2017 and Raj et al. 2013) shown that increase of gene copy numbers is in fact related to multiplication during merogony. Development beyond this phase of asexual multiplication is rather unlikely under the conditions given in our experiment.

We found that in comparison to E. tenella, E. acervulina sporozoites invade the cell and multiply at a higher rate during the first 24 hpi. However, the numbers of gene copies drop considerably by $96 \mathrm{hpi}$, showing dynamics of parasite multiplication for E. acervulina that distinctly differ from those of E. tenella. Thus, it appears likely that the various Eimeria species behave differently in in vitro culture and that general conclusions obtained from E. tenella as the only established model organism should be drawn with caution. The addition of more time points could be helpful to evaluate the dynamics of in vitro multiplication in more detail. Additional techniques can be applied to elucidate what happens during this period and if practical applications for future therapies can derivate from these results.

Nevertheless, we have shown parasite invasion success in this cell line. Therefore, MDBK cells could be further used as infection model for E. acervulina sporozoite cell invasion. Also, the use of RT-qPCR and other sensitive tools is recommended. More importantly, this cell line also supports $E$. tenella infection. This could be translated into comparative studies between both Eimeria species.

Further detailed quantitative and qualitative analyses should be performed to assess the suitability of MDBK culture as in vitro matrix for E. acervulina and developmental stages of other chicken Eimeria species.

Acknowledgements The authors wish to thank S. Gawlowska (Institute of Parasitology, University of Leipzig) for providing technical 
assistance; we are also grateful to M. Fritsche, B. Schneidewind, and R. Schumacher (Institute of Parasitology, University of Leipzig) for their excellent assistance as animal keepers. Many thanks also to R. Zhang (College of Animal and Veterinary Sciences, Southwest Minzu University) for her valuable help during laboratory work. The authors also wish to thank R. Schmäschke (Institute of Parasitology, University of Leipzig) for his valuable work with the preparation of animal permits.

Funding Open Access funding enabled and organized by Projekt DEAL. This work was funded by the Sudanese Ministry of Higher Education and Scientific Research (financial assistance to S. Taha), as well as by the Vietnamese Government Scholarship (financial support to T. Nguyen-Ho-Bao). This study was partially funded by the University of Leipzig Flexible Funds Program for Junior Researchers (project no. 43700871 for Z. Rentería-Solís).

\section{Declarations}

Ethics approval All procedures performed involving live animals were in accordance with the ethical standards of the local authorities (Landesdirektion Sachsen, permit no. A04/19).

Conflict of interest The authors declare no competing interests.

Open Access This article is licensed under a Creative Commons Attribution 4.0 International License, which permits use, sharing, adaptation, distribution and reproduction in any medium or format, as long as you give appropriate credit to the original author(s) and the source, provide a link to the Creative Commons licence, and indicate if changes were made. The images or other third party material in this article are included in the article's Creative Commons licence, unless indicated otherwise in a credit line to the material. If material is not included in the article's Creative Commons licence and your intended use is not permitted by statutory regulation or exceeds the permitted use, you will need to obtain permission directly from the copyright holder. To view a copy of this licence, visit http://creativecommons.org/licenses/by/4.0/.

\section{References}

Blake D, Knox J, Dehaeck B, Huntington B, Rathinam T, Ravipati V, Ayoade S, Gilbert W, Adebambo A, Jatau I, Raman M, Parker D, Rushton J, Tomley F (2020) Re-calculating the cost of coccidiosis in chickens. Vet Res 51:1. https://doi.org/10.1186/ s13567-020-00837-2

Blake D, Qin Z, Cai J, Smith A (2008) Development and validation of real-time polymerase chain reaction assays specific to four species of Eimeria. Avian Pathol 37:1

Bussiere Fl, Niepceron A, Sausset A, Esnault E, Silvestre A, Walker RA, Smith NC, Quéré P, Laurent F (2018) Establishment of an in vitro chicken epithelial cell line model to investigate Eimeria tenella gamete development. Parasit Vectors 11:44

Eckert J, Braun R, Shirley MW, Coudert P (1995) Biotechnology guidelines on techniques in coccidiosis research. COST European Cooperation in the Field of Scientific and Technical Research, Brussels

Györke A, Pop L, Cozma V (2013) Prevalence and distribution of Eimeria species in broiler chicken farms of different capacities. Parasite 20:5. https://doi.org/10.1015/parasite/2013052

Hiob L, Koethe M, Schares G, Goroll T, Daugschies A, Bangoura B (2017) Experimental Toxoplasma gondii and Eimeria tenella coinfection in chickens. Parasitol Res 116:11
Itagaki K, Hirayama N, Tsubokura M, Otsuki K (1974) Development of Eimeria tenella, E. brunetti and E. acervulina in cell cultures. Jap J Vet Sci 36:467-482

Jordan AB, Blake D, Beard J, Beharry A, Serrette L, Soleyn A, Sookhoo J, Blake L, Brown G, Oura C (2018) Molecular identification of Eimeria species in broiler chickens in Trinidad West Indies. Vet Sci 5:12

Kawahara F, Taira K, Nagai S, Onaga H, Onuma M, Nunoya T (2008) Detection of five avian Eimeria species by species-specific realtime polymerase chain reaction assay. Avian Dis 52:4

Khalafalla RE, Müller U, Shahiduzzaman M, Dyachenko V, Desouky AY, Alber G, Daugschies A (2011) Effects of curcumin (diferuloylmethane) on Eimeria tenella sporozoites in vitro. Parasitol Res 108:879-886

López-Osorio S, Chaparro-Gutiérrez JJ, Gómez-Osorio L (2020) Overview of poultry Eimeria life cycle and host-parasite interactions. Front Vet Sci 7:384

Marugán-Hernández V, Jeremiah G, Aguilar-Martins K, Burrell A, Vaughan S, Xia D, Randle N, Tomley F (2020) The growth of Eimeria tenella: characterization and application of quantitative methods to assess sporozoite invasion and endogenous development in cell culture. Front Cell Infect Microbiol 10:579833. https://doi.org/10.3389/fcimb.2020.579833

Moraes J, França M, Sartor A, Bellato V, de Moura A, Magalhães M, de Souza A, Miletti L (2015) Prevalence of Eimeria spp. in broilers by multiplex PCR in the southern region of Brazil on two hundred and fifty farms. Avian Dis 59:2

Naciri-Bontemps M (1976) Reproduction of the cycle of Coccidia Eimeria acervulina (Tyzzer, 1929) in cell cultures of chicken kidneys. Ann Rech Vét 7:223-230

Raj GD, Aarthi S, Selvabharathi R, Raman M, Blake DP, Tomley FM (2013) Real-time PCR-based quantification of Eimeria genomes: a method to outweigh underestimation of genome numbers due to PCR inhibition. Avian Pathol 42:4

Rentería-Solís Z, Zhang R, Taha SH, Daugschies A (2020) A modified method for purification of Eimeria tenella sporozoites. Parasitol Res 119:1429-1432

Strout R, Solis J, Smith S, Dunlop W (1965) In vitro cultivation of Eimeria acervulina (Coccidia). Exp Parasitol 17:3

Talebi A (2001) Inhibition of Eimeria acervulina sporozoite invasion by rabbit and chicken antisera using ISI assay. Arch Razi Ins 52:49-59

Thabet A, Alnassan AA, Daugschies A, Bangoura B (2015) Combination of cell culture and qPCR to assess the efficacy of different anticoccidials on Eimeria tenella sporozoites. Parasitol Res 114:6

Thabet A, Schmäschke R, Fertey J, Bangoura B, Schönfelder J, Lendner M, Ulbert S, Daugschies A (2019) Eimeria tenella oocysts attenuated by low energy electron irradiation (LEEI) induce protection against challenge infection in chickens. Vet Parasitol 266:18-26. https://doi.org/10.1016/j.vetpar.2019.01.001

Thabet A, Zhang R, Alnassan AA, Daugschies A, Bangoura B (2017) Anticoccidial efficacy testing: in vitro Eimeria tenella assays as replacement for animal experiments. Vet Parasitol 233:3. https:// doi.org/10.1016/j.vetpar.2016.12.005

Verma A, Verma M, Singh A (2020) Animal tissue culture principles and applications, 2nd edn. Animal Biotechnology, Boston, pp 269-293

Publisher's note Springer Nature remains neutral with regard to jurisdictional claims in published maps and institutional affiliations. 